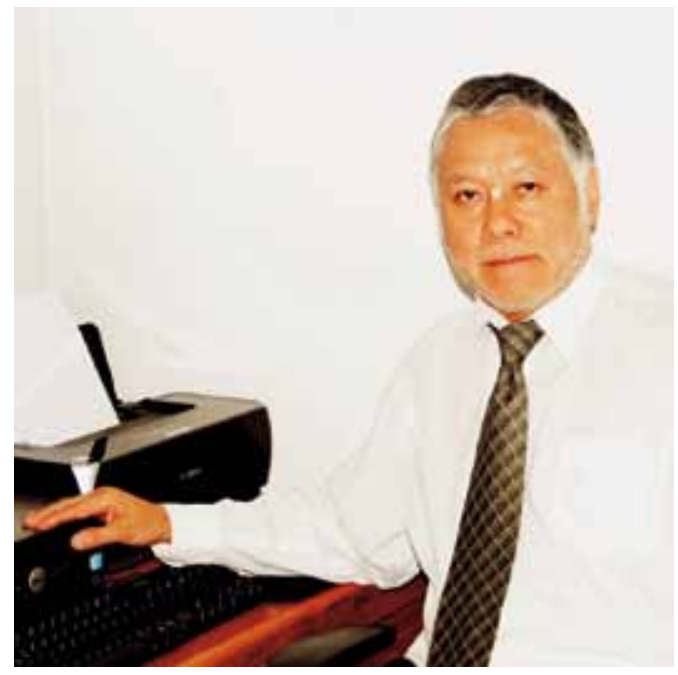

Vivimos en un país que está sujeto a múltiples catástrofes naturales dada su singular conformación geográfica. Alargado desde el norte seco hasta los fiordos australes y apretado entre el cordón montañoso y el océano Pacífico este territorio pone a prueba, de vez en cuando, nuestra estabilidad y nuestro temple.

Chile, con su «loca geografía» como la definió Benjamín Subercaseaux nos depara un territorio singular. El poeta Neruda se muestra apasionado por «las olas en sí mismas, me aterraron y me ensimismaron los voluntariosos maremotos y marejadas del océano chileno». Nuestra poetisa Gabriela Mistral, conocedora de nuestro suelo y nuestro carácter, agrega que «la naturaleza chilena es heroico-trágica» como consecuencia de su modo de habitar esta tierra.

De modo que resulta difícil hablar de desastres naturales, sin referirse al territorio, asumido como el bien público de mayor trascendencia para la humanidad en el siglo xxl, al ser reconocido como el eje estructurador de la secuencia de intercambios de energía que hacen posible la sobrevivencia de las especies animal, vegetal y humana en la Tierra.

Los chilenos sabemos que así como un año tiene otoño, invierno, primavera y verano, una década

ARQTO. HUMBERTO ELIASH D.

Vicedecano Facultad de Arquitectura y Urbanismo, Universidad de Chile

\title{
1. Geografía, urbanismo, arquitectura y diseño para emergencias \\ 2. Emergencia no debe ser sinónimo de improvisación
}

tiene terremoto, maremoto e inundaciones. El problema es saber cuándo vendrá cada uno de esos eventos. Con el avance tecnológico es posible que aprendamos a predecir mejor sus ocurrencias pero estamos seguros que no nos libraremos de ellos.

En todo el siglo xx y lo que va del siglo xxi los terremotos, tsunamis, erupciones volcánicas e inundaciones han producido más de 50.000 muertos. El pasado terremoto del 27 de febrero de 2010 de magnitud 8,8 con epicentro en Cobquecura, tuvo graves consecuencias sobre las ciudades chilenas de la zona centro sur lo cual nos obliga como país, como Universidad y como Facultad a revisar nuestra acción profesional sobre la forma de ver la geografía, el urbanismo, la arquitectura y el diseño. La realidad nos exige pensar que las situaciones de emergencia no debieran detonar sólo acciones improvisadas, sino debieran ser parte sustancial de nuestra educación ambiental, de nuestra planificación territorial y nuestra práctica profesional. Acciones destinadas a prevenir los desastres naturales y también acciones concretas que deriven en estrategias de acción frente a las urgencias, prototipos de viviendas y equipamiento de emergencia, soluciones de rápido traslado y montaje, etc. debieran ser objeto de estudio y creación en nuestra Facultad.
Esta edición de la revista de arquitectura, se presenta a la comunidad académica como una contribución tanto al conocimiento como al debate de formas de abordar la etapa de la emergencia frente a éste y otros posibles desastres y también a establecer criterios para abordar los procesos de reconstrucción de las ciudades y territorios afectados. Nuestra Facultad se encuentra abocada a un proceso reestructurador que abarca tanto su estructura organizacional como su planta académica. Uno de los pilares de esta reestructuración es cambiar la forma de concebir la relación entre las disciplinas que la componen: la geografía, el urbanismo, la arquitectura y el diseño constituyen el núcleo mediante el cual la Universidad de Chile piensa y diseña el territorio, las ciudades, los edificios y los objetos que constituyen el espacio humanizado de nuestro país, a través de una mirada multiescalar.

Necesitamos cambiar muchas cosas, y como dijo el poeta Gonzalo Rojas «ihay que cambiar el mundo sin que para ello le dejemos la iniciativa a los terremotos!». 